\title{
Tetra-Repeat Microsatellite Markers for the Masu Salmon (Oncorhynchus masou masou) and Its Application in Cross-Subspecies Amplification
}

\section{Shoichiro Yamamoto ${ }^{1, *}$, Tadahide Kurokawa ${ }^{2}$, Masashi Sekino ${ }^{3}$, Motoshige Yasuike ${ }^{3}$ and Kenji Saitoh $^{3}$}

1 National Research Institute of Aquaculture, Fisheries Research Agency, Nikko,

Tochigi 321-1661, Japan

2 Tohoku National Fisheries Research Institute, Fisheries Research Agency, Shiogama, Miyagi 985-0001, Japan; E-Mail: kurokawa@affrc.go.jp

3 National Research Institute of Fisheries Science, Fisheries Research Agency, Yokohama, Kanagawa 236-8648, Japan; E-Mails: sekino@affrc.go.jp (M.S.); yasuike@affrc.go.jp (M.Y.); ksaitoh@affrc.go.jp (K.S.)

* Author to whom correspondence should be addressed; E-Mail: ysho@affrc.go.jp; Tel.: +81-288-55-0055; Fax: +81-288-55-0064.

Received: 26 September 2013; in revised form: 11 November 2013 / Accepted: 12 November 2013 / Published: 21 November 2013

\begin{abstract}
We developed tetranucleotide-repeat microsatellite markers for the masu salmon (Oncorhynchus masou) complex. 454 pyrosequencing was used to discover repeat motifs, and seven polymorphic microsatellite-primer sets were identified. The number of alleles detected at each locus ranged from four to 24 and the expected heterozygosity varied from 0.57 to 0.92 . Cross-subspecies amplification for $O . m$. masou, O. m. ishikawae and $O$. $m$. subsp. was successful. These microsatellites can be utilized in studies of genetic structure, genetic diversity, and intra- and inter-subspecific hybridization, making a contribution to conservation and management of the Oncorhynchus masou complex.
\end{abstract}

Keywords: short tandem repeat; simple sequence repeat; 454 pyrosequencing; next-generation sequencer; Oncorhynchus masou 


\section{Introduction}

The masu salmon (Oncorhynchus masou) subspecies-complex (Salmonidae) is widely distributed in Far East Asia [1] and consists of four subspecies [2,3]. The subspecies are based on zoogeographic patterns and morphological characteristics; O. m. masou (Japanese name: sakura-masu), O. m. ishikawae (amago), O. m. subsp. (biwa-masu), and O. m. formosanus. O. m. masou and O. m. ishikawae have allopatric distributions, and are distinguishable by the spot-color pattern on their lateral sides: the former has black-spots while the latter has red-spots with sparse black-spots. $O$. $m$. subsp. is endemic to the Lake Biwa basin, central Honshu Island, Japan. Mitochondrial DNA analysis indicated that $O$. $m$. subsp. has a sister relationship with $O . m$. masou and O. m. ishikawae [4]. O. m. formosanus, which is endemic to Taiwan, has the world's southernmost distribution among the native salmonid fishes.

The masu salmon subspecies-complex supports important recreational and commercial fisheries throughout the Japanese archipelago. Hatchery-reared masu salmon have been released into many rivers in Japan to enhance the fish stocks available to local fishermen and recreational anglers. However, their genetic integrities and diversities have been ignored, resulting in accelerated hybridizations between wild and hatchery fish within the subspecies [5,6] and among subspecies [7,8]. In addition, habitat fragmentations by artificial damming occur frequently in Japanese rivers, causing reduced population sizes and genetic diversities of salmonid populations [5,9,10]. O. m. subsp. is "near threatened (NT)" on the red list of the ministry of the environment, Japan (2007) [11]. O. m. formosanus is listed as an endangered species by the Taiwanese government, and as a critically endangered species by the International Union for Conservation of Nature (IUCN) [12-14].

Several dinucleotide-type microsatellite markers for masu salmon have been reported [15]. At present, however, we do not know whether these loci can be used across the masu salmon subspecies-complex. In addition, it will be useful to develop microsatellite markers with larger repeat motifs which allow easier genotyping than dinucleotide microsatellites. In this study, we performed 454 pyrosequencing [GS-FLX+ System, 454 Life Sciences by Roche Diagnostics (Branford, CT, USA)] to isolate novel microsatellite markers from the $O . m$. masou genome, and evaluated their potential for conservation genetic applications, such as cross-subspecies amplifications and population genetic analyses.

\section{Results and Discussion}

Seven polymorphic microsatellite loci were isolated and deposited in GenBank (AB851460-AB851466; Table 1). The number of alleles detected at each locus ranged from four (OMAS-10) to 24 (OMAS-4) and the expected heterozygosity varied from 0.57 (OMAS-10) to 0.92 (OMAS-5). The intrapopulation diversities differed, with the mean number of alleles per population varying between 4.43 (Miya River: O. m. ishikawae) and 11.29 (Chitose River: O. m. masou), and the expected heterozygosity varied between 0.60 (Miya River) and 0.80 (Chitose River; Table 2). Among 27 Hardy-Weinberg equilibrium (HWE) tests, where OMAS-10 marker in O. m. ishikawae was omitted due to no allelic variation, six were significant after the false discovery rate correction of significant level for multiple comparisons. The observed departures, however, were neither locus nor population specific; therefore, we could not determine the cause of the HWE deviations. No marker pair showed 
evidence of departure from linkage equilibrium, indicating no significant allelic association between the markers. These microsatellites represent useful tools for population genetic applications, such as stock identification in the Oncorhynchus masou complex.

Table 1. Tetra-nucleotide microsatellite markers for Oncorhynchus masou complex.

\begin{tabular}{|c|c|c|c|c|c|c|}
\hline Marker & Motif $^{* 1}$ & & Primer sequences $\left(5^{\prime}-3\right)^{\prime}{ }^{* 2}$ & $T \mathbf{a}^{* 3}$ & $R_{\mathrm{A}}(\mathrm{bp}){ }^{* 4}$ & GenBank No. \\
\hline \multirow[t]{2}{*}{ OMAS-3 } & $(\mathrm{AGAC})_{14}$ & F-N & AGAGACAGATAGAGCCAGCCAG & 60 & $127-199$ & AB851460 \\
\hline & & $\mathrm{R}$ & TGATGAACGTTACGATTGGAAG & & & \\
\hline \multirow[t]{2}{*}{ OMAS-4 } & $(\mathrm{CACT})_{12}$ & F-P & TGCACATAAATTGAAGGCAAAC & 60 & $137-249$ & AB851461 \\
\hline & & $\mathrm{R}$ & GAGTCACCTGTCCCTCAGTACC & & & \\
\hline \multirow[t]{2}{*}{ OMAS-5 } & $(\mathrm{TCTG})_{13}$ & $\mathrm{~F}-\mathrm{F}$ & TTTTGCTGGTGACTCCCTAAAT & 60 & $236-348$ & AB851462 \\
\hline & & $\mathrm{R}$ & ATTTGCAGAGGGAAACAGACAT & & & \\
\hline \multirow[t]{2}{*}{ OMAS-7 } & $(\mathrm{AGAC})_{16}$ & $\mathrm{~F}-\mathrm{N}$ & GGGAAAGAAAGGAGATTGAGAGA & 60 & $235-295$ & AB851463 \\
\hline & & $\mathrm{R}$ & GACCCTGGTAGAACTGCAAACT & & & \\
\hline \multirow[t]{2}{*}{ OMAS-10 } & $(\mathrm{GAGG})_{6}$ & $\mathrm{~F}-\mathrm{V}$ & AGCAAAGGGAGATAAGGTAGGG & 60 & $305-313$ & AB851464 \\
\hline & & $\mathrm{R}$ & CATCTTCATTCAGAGGGGTAGG & & & \\
\hline \multirow[t]{2}{*}{ OMAS-14 } & $(\mathrm{GAGT})_{7}$ & $\mathrm{~F}-\mathrm{F}$ & ATTGTTAGAGCGGGAGACGATA & 60 & $98-138$ & AB851465 \\
\hline & & $\mathrm{R}$ & TCCCCAGAATTGTTAGCTGAGT & & & \\
\hline \multirow[t]{2}{*}{ OMAS-18 } & $(\mathrm{ATCA})_{9}$ & $\mathrm{~F}-\mathrm{V}$ & CACACAAAGAAAACCTTGAATGA & 60 & $113-157$ & AB851466 \\
\hline & & $\mathrm{R}$ & AACGTGACTGCACAACAAAGTT & & & \\
\hline
\end{tabular}

$*^{1}$ : Repeat counts are based on the individual from which the microsatellite-primer sequences were obtained;

$*^{2}$ : The forward primer of each primer set was 5'-end-labeled with 6-FAM (denoted as F-F), VIC (F-V), NED (F-N) or PET (F-P) fluorescent dye; ${ }^{*}$ : Optimized annealing temperature. ${ }^{4}$ : Range of allele sizes.

\section{Experimental Section}

\subsection{Isolation of Microsatellite Markers}

Total genomic DNA from $O$. m. masou (blood cell) was extracted by proteinase $\mathrm{K}$ digestion, phenol/chloroform extraction, and ethanol precipitation. We prepared a shotgun library from $1.0 \mu \mathrm{g}$ of genomic DNA following the 454-Roche protocol. Pyrosequencing was conducted on one-fourth picotiter plate. We searched for microsatellites and microsatellite-flanking PCR primer sequences using Auto-Primer [16]. A 454 run generated 175,689 sequence reads (63,019,585 bp) from $c a$. $5.0 \times 10^{5}$ beads with clonally amplified DNA, resulting in 1937 contigs and 129,759 singletons. Auto-Primer proposed 242 PCR primer sets for tetra-nucleotide microsatellites. We selected 18 primer sets designed for amplification of "perfect-type" tetra-nucleotide repeats (i.e., repeat arrays without interruption by a non-repeat element); 11 were rejected because of poor amplification or difficulty in allele scoring. The remaining seven sets were applicable for estimation of polymorphism (Table 1). 
Table 2. Genetic diversity statistics for the three subspecies of Oncorhynchus masou.

\begin{tabular}{|c|c|c|c|c|c|c|c|c|c|}
\hline Subspecies & River/Lake & Statistics of polymorphisms ${ }^{* 1}$ & OMAS-3 & OMAS-4 & OMAS-5 & OMAS-7 & OMAS-10 & OMAS-14 & OMAS-18 \\
\hline \multirow{5}{*}{ Oncorhynchus masou masou } & \multirow{5}{*}{ Chitose River } & $H_{\mathrm{o}}$ & 0.86 & 0.93 & 0.73 & 0.90 & 0.50 & 0.67 & 0.31 \\
\hline & & $H_{\mathrm{E}}$ & 0.89 & 0.90 & 0.84 & 0.86 & 0.62 & 0.75 & 0.74 \\
\hline & & HW_P & 0.12 & $0.01 *$ & $0.00 *$ & 0.09 & 0.10 & 0.02 & $0.00 *$ \\
\hline & & Number of Alleles & 15 & 17 & 17 & 12 & 3 & 8 & 7 \\
\hline & & $n$ & 43 & 42 & 40 & 42 & 42 & 43 & 35 \\
\hline \multirow{5}{*}{ Oncorhynchus masou ishikawae } & \multirow{5}{*}{ Miya River } & $H_{\mathrm{o}}$ & 0.46 & 0.83 & 0.75 & 0.24 & - & 0.60 & 0.15 \\
\hline & & $H_{\mathrm{E}}$ & 0.44 & 0.85 & 0.75 & 0.61 & - & 0.44 & 0.14 \\
\hline & & HW_P & 1.00 & $0.00 *$ & 0.02 & $0.00 *$ & - & 0.02 & 1.00 \\
\hline & & Number of Alleles & 5 & 8 & 6 & 6 & 1 & 2 & 3 \\
\hline & & $n$ & 48 & 48 & 48 & 41 & 48 & 48 & 48 \\
\hline \multirow{5}{*}{ Oncorhynchus masou subsp. } & \multirow{5}{*}{ Lake Biwa } & $H_{\mathrm{o}}$ & 0.78 & 0.87 & 0.78 & 0.78 & 0.06 & 0.53 & 0.81 \\
\hline & & $H_{\mathrm{E}}$ & 0.81 & 0.89 & 0.86 & 0.85 & 0.06 & 0.62 & 0.78 \\
\hline & & HW_P & 0.66 & 0.80 & 0.10 & 0.11 & 1.00 & 0.60 & 0.98 \\
\hline & & Number of Alleles & 9 & 14 & 11 & 9 & 2 & 7 & 7 \\
\hline & & $n$ & 32 & 31 & 32 & 32 & 32 & 32 & 32 \\
\hline \multirow{5}{*}{$\begin{array}{c}\text { Oncorhynchus masou masou } \\
\text { (hatchery stock) }\end{array}$} & \multirow{5}{*}{ Oohara River } & $H_{\mathrm{o}}$ & 0.79 & 0.64 & 0.84 & 0.71 & 0.56 & 0.79 & 0.14 \\
\hline & & $H_{\mathrm{E}}$ & 0.71 & 0.69 & 0.86 & 0.67 & 0.53 & 0.68 & 0.27 \\
\hline & & HW_P & 0.56 & 0.47 & 0.02 & 0.69 & 0.91 & 0.37 & $0.00 *$ \\
\hline & & Number of Alleles & 7 & 6 & 8 & 4 & 3 & 4 & 3 \\
\hline & & $n$ & 39 & 39 & 38 & 38 & 39 & 39 & 37 \\
\hline \multirow{3}{*}{ Average } & \multirow{3}{*}{-} & $H_{\mathrm{o}}$ & 0.72 & 0.82 & 0.77 & 0.66 & 0.37 & 0.65 & 0.35 \\
\hline & & $H_{\mathrm{E}}$ & 0.71 & 0.83 & 0.83 & 0.75 & 0.40 & 0.62 & 0.48 \\
\hline & & Number of Alleles & 9 & 11 & 11 & 8 & 2 & 5 & 5 \\
\hline
\end{tabular}

$*{ }^{1}, H \mathrm{o}$ : observed heterozygosity; $H_{\mathrm{E}}$ : expected heterozygosity; HW_P: probability value of Hardy-Weinberg equilibrium (HWE) testing. Significant HWE departure after the false discovery rate correction of significance level for multiple comparisons is indicated by an asterisk; $n$ : number of genotyped individuals. 


\subsection{PCR Amplification and Genotyping}

Three wild population samples (O. m. masou from the Chitose River, Hokkaido Island, Japan; O. $m$. ishikawae from the Miya River, central Honshu, Japan; and $O$. $m$. subsp. from Lake Biwa, central Honshu, Japan) and one hatchery-reared stock sample (O. m. masou from the Ohara River, northern Honshu, Japan) were used for polymorphism detection. After conjugating 6-FAM, HEX, NED or PET fluorescent dyes (Applied Biosystems, Life Technologies, Carlsbad, CA, USA) to the 5'-end of each forward primer, we performed multiplex PCR for the seven selected primer sets using a Qiagen multiplex PCR kit (Qiagen, Limburg, The Netherlands). The $10-\mu \mathrm{L}$ reaction mixture contained $1 \times$ Qiagen multiplex PCR master mix, $0.2 \mu \mathrm{M}$ of each primer, $2 \mu \mathrm{L}$ of distilled water, and $1 \mu \mathrm{L}$ of DNA solution. Amplifications were carried out in a GeneAmp PCR System 2700 thermal cycler (Applied Biosystems), according to the supplier's instructions (Qiagen multiplex PCR kit; Qiagen): initial denaturation at $95^{\circ} \mathrm{C}$ for $15 \mathrm{~min}$; followed by 30 cycles of denaturation at $94{ }^{\circ} \mathrm{C}(30 \mathrm{~s})$, annealing $\left(60^{\circ} \mathrm{C}\right.$, $90 \mathrm{~s}$ ) and extension $\left(72{ }^{\circ} \mathrm{C}, 60 \mathrm{~s}\right)$; with a final extension $\left(60^{\circ} \mathrm{C}, 30 \mathrm{~min}\right)$. PCR fragments and GeneScan 600LIZ size standards were resolved on an ABI PRISM 3730xl sequencer (Applied Biosystems, Life Technologies). Allele size was determined using GeneMapper v4.1 (Applied Biosystems, Life Technologies).

\subsection{Data Analysis}

Polymorphism statistics, including the observed/expected heterozygosities, were calculated in Arlequin v3.5 [17]. The Hardy-Weinberg equilibrium of markers/populations was tested using Fisher's exact test with the Markov chain method (Markov chain steps: $10^{5}$; Dememorization: $10^{5}$ ). We also examined linkage equilibrium between markers (likelihood-ratio test: $10^{4}$ permutations). Critical significance levels for multiple testing were adjusted following the false discovery rate [18].

\section{Conclusions}

We report the isolation and characterization of seven polymorphic microsatellite loci for the Oncorhynchus masou complex. All seven markers used were polymorphic. Cross-subspecies amplification for O. m. masou, O. m. ishikawae and O.m. subsp. was successful. These microsatellites can be utilized in studies of genetic structure, genetic diversity, and intra- and inter-subspecific hybridization, making a contribution to conservation and management of the Oncorhynchus masou complex.

\section{Acknowledgments}

We thank K. Kawamura, T. Kikko, S. Sato and A. Nawata for donating masu salmon samples. We also thank M. Yoshida and T. Ootsuka for their assistance with the DNA analysis. This study was supported by Grants-in-Aid for Scientific Research (Nos. 22510251 and 25450290 to S. Y., 25450295 to T. K.) from the Japan Society for the Promotion of Science.

\section{Conflicts of Interest}

The authors declare no conflict of interest. 


\section{References}

1. Kato, F. Life Histories of Masu and Amago Salmon (Oncorhynchus masou and Oncorhynchus rhodurus). In Pacific Salmon Life Histories; Groot, C., Margolis, L., Eds.; UBC Press: Vancouver, BC, Canada, 1991; pp. 447-520.

2. Taki, Y.; Kohno, H.; Sakamoto, K.; Hosoya, K. Illustrated Fishes in Colour, revised edition; Hokuryukan: Tokyo, Japan, 2005.

3. Yan, H.Y. Threatened fishes of the world: Oncorhynchus masou formosanus (Jordan \& Oshima, 1919) (Salmonidae). Environ. Biol. Fishes 2000, 57, 314.

4. Oohara, I.; Okazaki, T. Genetic relationship among three subspecies of Oncorhynchus masou determined by mitochondrial DNA sequence analysis. Zool. Sci. 1996, 13, 189-198.

5. Kawamura, K.; Kubota, M.; Furukawa, M.; Harada, Y. The genetic structure of endangered indigenous populations of the amago salmon, Oncorhynchus masou ishikawae, in Japan. Conserv. Genet. 2007, 8, 1163-1176.

6. Kawamura, K.; Furukawa, M.; Kubota, M.; Harada, Y. Effects of stocking hatchery fish on the phenotype of indigenous populations in the Amago salmon Oncorhynchus masou ishikawae in Japan. J. Fish Biol. 2012, 81, 94-109.

7. Yamazaki, Y.; Shimada, N.; Tago, Y. Detection of hybrids between masu salmon Oncorhychus masou masou and amago salmon O. m. ishikawae occurred in the Jinzu River using a random amplified polymorphic DNA technique. Fish. Sci. 2005, 71, 320-326.

8. Kuwahara, M.; Takahashi, H; Kikko, T.; Kurumi, S.; Iguchi, K. Introgression of Oncorhynchus masou subsp. (Biwa salmon) genome into lake-run O. m. ishikawae (amago salmon) introduced into Lake Biwa, Japan. Ichthyol. Res. 2012, 59, 195-201.

9. Yamamoto, S.; Morita, K.; Koizumi, I.; Maekawa, K. Genetic differentiation of white-spotted charr (Salvelinus leucomaenis) populations after habitat fragmentation: Spatial-temporal changes in gene frequencies. Conserv. Genet. 2004, 5, 529-538.

10. Miyahara, H.; Yamada, H.; Sato, T.; Harada, Y.; Yamamoto, S.; Kawamura, K. Mitochondrial-nuclear discordance in the amago salmon, Oncorhynchus masou ishikawae, in the River Miya, Japan. Conserv. Genet. 2012, 13, 1343-1353.

11. Ministry of the Environment, Japan. Red List. Brackish and Freshwater Fishes. Available online: http://www.env.go.jp/press/file_view.php?serial=9944\&hou_id=8648 (accessed on 19 November 2011).

12. Lin, Y-S.; Yang, P.S.; Liang, S.H.; Tsao, S.H.; Juang, L.C. Ecological studies of Formosan landlocked salmon, Oncorhynchus masou formosanus. I. Preliminary study on the relationship between population distribution and environmental factors in Wuling Farm. Ecological Research No. 23. 1987, Council of Agriculture, executive Yuan, Taipei, Taiwan.

13. Kottelat, M. Oncorhynchus Formosanus. In IUCN 2013. IUCN Red List of Threatened Species. Ver. 2013.1. 1996. Available online: http://www.iucnredlist.org (accessed on 15 November 2013).

14. Sato, T.; Gwo, J.-C. Demographic and genetic consequences of population subdivision in Formosa land-locked salmon Oncorhynchus masou formosanus, the southernmost subspecies of the salmonids. Ichthyol. Res. 2011, 58, 209-216. 
15. Noguchi, D.; Ikeda, M.; Nakajima, M.; Taniguchi, N. Isolation and characterization of microsatellite DNA markers for population genetics study of masu salmon, Oncorhynchus masou masou. Fish Genet. Breed. Sci. 2003, 33, 61-66.

16. Nakamura, Y.; Shigenobu, Y.; Sugaya, T.; Kurokawa, T.; Saitoh, K. Automated screening and primer design of fish microsatellite DNA loci on pyrosequencing data. Ichthyol. Res. 2013, 60, 184-187.

17. Excoffier, L.; Lischer, H.E.L. Arlequin suite ver 3.5: A new series of programs to perform population genetic analyses under Linux and Windows. Mol. Ecol. Resour. 2010, 10, 564-567.

18. Benjamini, Y.; Hochberg, Y. Controlling the false discovery rate: A practical and powerful approach to multiple testing. J. R. Stat. Soc. Ser. B 1995, 57, 289-300.

(C) 2013 by the authors; licensee MDPI, Basel, Switzerland. This article is an open access article distributed under the terms and conditions of the Creative Commons Attribution license (http://creativecommons.org/licenses/by/3.0/). 